\title{
A functional RNase $P$ protein subunit of bacterial origin in some eukaryotes
}

Lien B. Lai (1, 2), Pilar Bernal-Bayard (3), Gireesha Mohannath (1, 2), Stella M. Lai (1, 2), Venkat Gopalan (1, 2) and Agustín Vioque (3)

(1)Department of Biochemistry, The Ohio State University, Columbus, OH 43210, USA

(2)Center for RNA Biology, The Ohio State University, Columbus, OH 43210, USA

(3)Instituto de Bioquímica Vegetal y Fotosíntesis, Universidad de Sevilla and CSIC, Américo Vespucio 49, 41092 Sevilla, Spain

\section{Abstract}

RNase $\mathrm{P}$ catalyzes $5^{\prime}$-maturation of tRNAs. While bacterial RNase $\mathrm{P}$ comprises an RNA catalyst and a protein cofactor, the eukaryotic (nuclear) variant contains an RNA and up to ten proteins, all unrelated to the bacterial protein. Unexpectedly, a nuclear-encoded bacterial RNase P protein (RPP) homolog is found in several prasinophyte algae including Ostreococcus tauri. We demonstrate that recombinant $O$. tauri RPP can functionally reconstitute with bacterial RNase P RNAs (RPRs) but not with O. tauri organellar RPRs, despite the latter's presumed bacterial origins. We also show that O. tauri PRORP, a homolog of Arabidopsis PRORP-1, displays tRNA 5'-processing activity in vitro. We discuss the implications of the striking diversity of RNase $P$ in $O$. tauri, the smallest known free-living eukaryote.

\section{Keywords}

RNase P diversity - Prasinophyte - pre-tRNA processing

\section{Introduction}

Despite a shared primary function in $5^{\prime}$-end tRNA maturation, the make-up of the RNase $P$ ribonucleoprotein (RNP) complex is evolutionarily divergent (Evans et al. 2006; Walker and Engelke 2006; Esakova and Krasilnikov 2010; Jarrous and Gopalan 2010; Lai et al. 2010; Liu and Altman 2010). While there is a single catalytic RNase P RNA (RPR) subunit that shares a common ancestry in all three domains of life, the RNase P protein (RPP) component is variable in number and identity. In Bacteria, RNase $\mathrm{P}$ is associated with a single protein subunit ( $14 \mathrm{kDa}$ ) while up to five RPPs have been reported in Archaea. Eukarya has up to ten RPPs; five of them are homologous to archaeal RPPs, but none have homology to the bacterial RPP.

Organellar RNase $\mathrm{P}$ presents a more complicated scenario. Despite the presence of a bacterial RPR-like gene in some algal mitochondria and chloroplast genomes (Lai et al. 2010), no bacterial RPP homolog has been reported in eukaryotes. The organellar RPPs characterized in yeast and human mitochondria are distinct from any of the known RPPs (Morales et al. 1992; Holzmann et al. 2008). Although a pioneering study demonstrated that human mitochondrial $(\mathrm{mt})$ RNase P is devoid of RNA and functions as a patchwork of three proteins (Holzmann et al. 2008), recent work suggests the co-existence of both a protein-only and an RNP-based RNase P (Wang et al. 2010). In another breakthrough, the organellar precursor tRNA (pretRNA) 5'-processing activity in Arabidopsis was shown to be associated with a single nuclear-encoded polypeptide (PRORP-1), which is homologous to one of the three proteins in the protein-only form of human $\mathrm{mt}$ RNase $\mathrm{P}$ (Gobert et al. 2010). 
Given this extraordinary diversity in the subunit make-up of RNase $P$, we inquired into the RNase $P$ variants that might be present in Ostreococcus tauri, a unicellular green alga. Our focus on $O$. tauri was inspired by three reasons: it is the smallest known free-living eukaryote; it is a member of the Prasinophyceae, an ancient sister clade to land plants; and its nuclear and organellar genome sequences are available. Moreover, since its nuclear genome is one of the smallest $(12.5 \mathrm{Mb})$ and most compact (1.5 kb/gene) among eukaryotes, $\mathrm{O}$. tauri presents a unique opportunity to inquire if there is any correlation between the number of RNase $P$ variants and genome size. The recently sequenced nuclear genomes of $O$. tauri and four other prasinophytes (Derelle et al. 2006; Palenik et al. 2007; Worden et al. 2009) unexpectedly reveal the presence of a hypothetical protein that is homologous to the bacterial RPP. We demonstrate here that a recombinant version of this bacterial-like RPP from 0 . tauri assembles with bacterial RPRs to generate holoenzymes capable of tRNA 5'-processing, a finding which represents the first discovery of an active bacterial-like RNase P protein subunit in eukaryotes. Although we document evidence for the expression of O. tauri RPP in its native context, the biological partners and function of O. tauri RPP (or its prasinophyte homologs) remain to be identified. We also found that a recombinant O. tauri PRORP, a homolog of Arabidopsis PRORP-1, displays pre-tRNA cleavage in vitro. We discuss the implications of the diversity of RNase $\mathrm{P}$ isoforms in O. tauri.

\section{Materials and methods}

\section{Culturing of 0 . tauri}

O. tauri RCC745 cells were obtained from Roscoff Culture Collection and grown on K medium at $25^{\circ} \mathrm{C}$ (Keller et al. 1987).

\section{Cloning, expression and purification of O. tauri RPP}

The coding region of $\mathrm{O}$. tauri RPP was amplified by PCR from genomic DNA using OtC5-2F (5'GATCCATGGCGTCGGGGGGGTGGG-3') and OtC5-2R (5'-GTCACGTGTTGGTCGGCGTCGGTTCTGGC-3'). The Ncol and Pmll recognition sites (underlined) introduced by the primers facilitated cloning of the PCR product into $\mathrm{pET}-33 \mathrm{~b}$ at the Ncol and filled-in Eagl sites, respectively, to create a C-terminal His6-tag fusion. The resulting plasmid ( $\mathrm{pET}$-33b-OtRPP) was confirmed by sequencing before it was used to transform Escherichia coli BL21(DE3) Rosetta cells (Novagen). A single transformant was grown to Abs600 0.6 at $37^{\circ} \mathrm{C}$ in LB medium supplemented with $35 \mu \mathrm{g} / \mathrm{mL}$ chloramphenicol $+35 \mu \mathrm{g} / \mathrm{mL}$ kanamycin and induced with 0.5 mM IPTG for $20 \mathrm{~h}$ at room temperature $\left(\sim 23^{\circ} \mathrm{C}\right)$. For purification, a $125 \mathrm{~mL}$ culture pellet was resuspended in $12.5 \mathrm{~mL}$ Buffer $A$ [20 mM sodium phosphate $(\mathrm{pH} 7.2), 4 \mathrm{M}$ urea, $0.2 \mathrm{mM}$ PMSF], sonicated, and centrifuged at 30,000 g for $20 \mathrm{~min}$ at $4^{\circ} \mathrm{C}$. The crude extract was passed through a $0.45 \mu \mathrm{m}$ syringe filter and loaded onto a $1 \mathrm{~mL}$ HiTrap CM-Sepharose column (GE Healthcare). All subsequent solutions for purification contained $20 \mathrm{mM}$ sodium phosphate, pH 7.2. Using an FPLC (Pharmacia) apparatus, a linear reverse-urea gradient (4-0 M urea) was employed to renature the proteins before their elution with a linear 0-1.5 M $\mathrm{NaCl}$ gradient. The peak fractions ( 0.75 to $1.1 \mathrm{M} \mathrm{NaCl})$ were pooled, diluted to $0.5 \mathrm{M} \mathrm{NaCl}$, and loaded onto a $1 \mathrm{~mL}$ HiTrap Chelating column (GE Healthcare) equilibrated with NiSO4. When a linear 0-0.5 M imidazole gradient was used, we observed co-elution of three proteins at $0.35 \mathrm{M}$ imidazole. To further purify the proteins individually, the peak imidazole fractions were pooled and subjected to a $12 \%(\mathrm{w} / \mathrm{v})$ polyacrylamide-SDS gel electrophoresis. Each protein band was excised after identification by Zn2+-based reverse staining of the gel (Hardy and Castellanos-Serra 2004), and the protein extracted by soaking crushed gel fragments in assay buffer (see "RNase P assay"). The concentration of O. tauri RPP was calculated using its extinction coefficient and absorbance at $280 \mathrm{~nm}$. 


\section{Computational searches}

The O. tauri chloroplast RPR gene was identified by BLAST (Altschul et al. 1990) in the chloroplast genome sequence (Palenik et al. 2007) querying with the sequence AGTCCG, which corresponds to the $5^{\prime}$ half of the universally conserved helix P4. The list of hits was then examined manually for the presence of the $3^{\prime}$ half (TCGGC) of the P4 helix within 200 nts downstream to AGTCCG, as has been observed with most bacterial RPRs.

The presence of homologs to experimentally validated eukaryal RPPs in the five sequenced prasinophyte genomes was analyzed at the DOE Joint Genome Institute server (http://genome.jgi.doe.gov/) using BLAST searches and the known sequences of yeast/human (eukaryotic nuclear) RPPs as queries.

\section{Cloning of O. tauri organellar RPRs and pre-tRNALeu}

To clone the RPRs, the encoding sequences were amplified by PCR from genomic DNA using gene-specific primers; a restriction site was engineered into each reverse primer (underlined sequence). Each PCR fragment was then digested with the corresponding restriction enzyme before being inserted downstream of the T7 promoter in PBT7 (Tsai et al. 2002) at the Stul site and the restriction site introduced in the reverse primer. The primers for cloning $O$. tauri mitochondrial RPR were OtMtRPR-F (5'GATAAGATGCCGCATGTCCG-3') and OtMtRPR-2R (5'-GACCCGGGATAAGATGCTTATAAGC-3'); and for O. tauri chloroplast RPR, OtCpRPR-F (5'-AAAAATAAAGAGTGGTTGCAG-3') and OtCpRPR-R (5'GTGGATCCAAAAATAAAGTATAAGCCG-3'). Similarly, the gene encoding $O$. tauri mitochondrial pre-tRNALeu (GAG) was amplified with OtpLeu-F (5'-ATAATAATACATTACAGAATTTTTTTTGCAAAAG-3') and OtpLeu-R (5'ATGCATCCTGGTGCAAAAGGTGGGACTTG-3'); the pre-tRNALeu PCR fragment was cloned into the Stul site of pBT7. The sequence depicted in bold font in OtpLeu-F was added to create an extended $5^{\prime}$-leader sequence (from 21 to $29 \mathrm{nts}$ ) that would permit easy separation of RNase P-mediated cleavage products by gel electrophoresis. The cloned plasmids were confirmed by sequencing before further use.

\section{In vitro transcription}

Plasmids were first linearized by digesting pBT7-OtMtRPR with Smal, pBT7-OtCpRPR with BamHI, pBT7OtMtpLeu and pUC19-NtCppGly (Raj and Gopalan, unpublished) with BstNI, and pUC19-EcopTyr (Vioque et al. 1988) with Fokl. These plasmids then served as templates for T7 RNA polymerase-mediated run-off transcription using established protocols (Vioque et al. 1988). Templates encoding for the RPRs from Synechocystis PCC6803 and Anabaena PCC7120 were prepared as described previously (Pascual and Vioque 1999b). To obtain internally radiolabeled pre-tRNAs, these in vitro transcription reactions were supplemented with either 32P-ATP or -GTP.

\section{RNase $\mathrm{P}$ assays}

The pre-tRNA processing assays were performed largely as described elsewhere (Vioque et al. 1988). E. coli RPR was pre-folded by first incubating in water at $50^{\circ} \mathrm{C}$ for $50 \mathrm{~min}, 37^{\circ} \mathrm{C}$ for $10 \mathrm{~min}$, then in $1 \times$ assay buffer

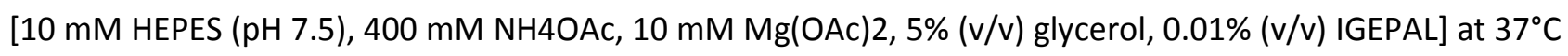
for $30 \mathrm{~min}$. The RNase P holoenzyme was reconstituted by incubating $1 \mathrm{nM}$ folded RPR with either $10 \mathrm{nME}$. coli RPP or O. tauri RPP in $1 \times$ assay buffer for $10 \mathrm{~min}$ at $37^{\circ} \mathrm{C}$. Assays were then initiated by adding $100 \mathrm{nM}$ pre-tRNA (a trace amount of which was internally labeled) and the incubation continued at $37^{\circ} \mathrm{C}$. Reactions were quenched with an equal volume of $2 \times$ urea dye [7 M urea, $1 \mathrm{mM}$ EDTA, 0.05\% (w/v) xylene cyanol, $0.05 \%(\mathrm{w} / \mathrm{v})$ bromophenol blue, and $10 \%(\mathrm{v} / \mathrm{v})$ phenol] and separated on an $8 \%(\mathrm{w} / \mathrm{v})$ polyacrylamide gel 
containing $7 \mathrm{M}$ urea. The extent of cleavage was visualized by phosphorimaging on the Typhoon (GE Healthcare) and quantitated by ImageQuant (GE Healthcare) to yield the initial velocity/turnover data.

For the single-turnover assays involving cyanobacterial RPRs and O. tauri RPP (Fig. 3), the RNase P holoenzyme was reconstituted with $50 \mathrm{nM}$ RPR and $500 \mathrm{nM}$ RPP and incubated with trace amounts of 32Plabeled E. coli pre-tRNATyr at $37^{\circ} \mathrm{C}$ for $45 \mathrm{~min}$ in $10 \mathrm{mM}$ HEPES (pH 7.5), $50 \mathrm{mM} \mathrm{MgCl2}$. Reactions were quenched and analyzed as described above.

Single-turnover conditions were also employed for the assays with recombinant O. tauri PRORP (Fig. 7). Approximately $2 \mu \mathrm{M}$ recombinant $\mathrm{O}$. tauri PRORP was assayed for $30 \mathrm{~min}$ at $23^{\circ} \mathrm{C}$ as described elsewhere for Arabidopsis PRORP-1 (Gobert et al. 2010), with either internally labeled O. tauri pre-tRNALeu or tobacco chloroplast pre-tRNAGly ( $<1 \mathrm{nM})$ as the substrate. Reactions were quenched and analyzed as described above.

\section{Genetic complementation}

The function of $\mathrm{O}$. tauri RPP was analyzed by genetic complementation of the $\mathrm{E}$. coli thermosensitive rnpA49 mutation (Schedl and Primakoff 1973). E. coli BL21(DE3)A49 (Guerrier-Takada et al. 1995) was transformed with pET-33b-OtRPP, which expresses His6-tagged O. tauri RPP, and growth was assessed at $30^{\circ} \mathrm{C}$ (permissive) and $43^{\circ} \mathrm{C}$ (non-permissive). Cells transformed with pET-33b served as the negative control, while those transformed with PARE7, which express the wild type E. coli RPP (Vioque et al. 1988), were employed as the positive control. After obtaining the transformants at $30^{\circ} \mathrm{C}$, individual colonies were grown overnight at $30^{\circ} \mathrm{C}$ in LB media with the following supplements: BL21(DE3)A49/pET-33b and BL21(DE3)A49/pET-33b-OtRPP, $4 \mu \mathrm{g} / \mathrm{mL}$ tetracycline $+50 \mu \mathrm{g} / \mathrm{mL}$ kanamycin; BL21(DE3)A49/pARE7, 4 $\mu \mathrm{g} / \mathrm{mL}$ tetracycline $+100 \mu \mathrm{g} / \mathrm{mL}$ ampicillin. Tenfold serial dilutions of these cultures in fresh media were then plated on LB agar containing $4 \mu \mathrm{g} / \mathrm{mL}$ tetracycline, and growth was assessed after incubation at 30 or $43^{\circ} \mathrm{C}$ for $16 \mathrm{~h}$.

\section{Antibody generation and western blotting}

Approximately $3 \mathrm{mg}$ of affinity-purified $\mathrm{O}$. tauri RPP was loaded on a preparative polyacrylamide gel, and the three $\mathrm{O}$. tauri RPP fragments were excised and eluted together. To raise polyclonal antisera, $1 \mathrm{mg}$ of such purified protein was injected subcutaneously into a white New Zealand rabbit. Antibodies were generated using standard procedures at the Animal Experimentation Facility, University of Sevilla. The antibodies were affinity purified (Harlow and Lane 1988) before use in western analysis. After separating 30 $\mu \mathrm{g}$ of total soluble $\mathrm{O}$. tauri protein on a $12 \%(\mathrm{w} / \mathrm{v})$ polyacrylamide-SDS gel, western blotting was performed using standard procedures. An anti-rabbit IgG-peroxidase (Sigma) was employed as the secondary antibody and the antigen detected using the SuperSignal West Femto Chemiluminescent substrate (Thermo Scientific).

\section{RT-PCR}

Total RNA was isolated from O. tauri RCC745 using either TriReagent LS (Sigma-Aldrich) or the RNeasy Plant Mini Kit (Qiagen) and treated with DNase I before proceeding. The O. tauri RPP transcript was reverse transcribed using OtC5rtpcr-R (5'-GTCACGGGTTGGTCGGC-3'; the sequence complementary to the termination codon is underlined) and BluePrint Reverse Transcriptase (Takara). Subsequently, with this RT reaction product as the template, PCR was performed with Ex Taq HS DNA Polymerase (Takara), and OtC5rtpcr-R + OtC5rtpct-F (5'-GATGGCGTCGGGGGG-3'; the start codon is underlined). The 0 . tauri 
organellar RPRs were reverse transcribed using SuperScript ${ }^{\mathrm{TM}}$ II Reverse Transcriptase (Invitrogen) and OtR2 (5'-ATAAGCCGAATTCTGTAACC-3') for the mitochondrial RPR and OTCPR1 (5'-AGCCGAATTCTGTGCGTGTGG$\left.3^{\prime}\right)$ for the chloroplast RPR. PCR was then carried out using the RT reactions as templates and Go Taq Flexi DNA Polymerase (Promega) with OtR2 + OtF3 (5'-AAGATGCCGCATGTCCGC-3') and OTCPR1 + OTCPF1 (5'GAGTGGTTGCAGAAATATTTAAG-3'), respectively.

\section{Cloning, overexpression and purification of O. tauri PRORP}

We first amplified by PCR the sequence that was initially annotated to encode OtPRORP (1.2 kb), using as template $O$. tauri genomic DNA and as primers OtPRORP-F (5'-CTAGCATATGGCGAGCGCG-3') and OtPRORP$\mathrm{R}$ (5'-CTGGATCCTTATTGCTTGCACGCACA-3'). As multiple shorter fragments were also amplified, the $1.2 \mathrm{~kb}$ fragment was gel-purified and cloned into the Stul site of pBT7. This clone then served as the template for PCR amplification with OtPRORP-2F (5'-ATACCATGGCGAGCGCGGAGTGCGTTCGTGGTGATAAGGCTGTGG-3') and OtPRORP-2R (5'-TCAGTGGTGGTGGTGGTGGTGTTGCTTGCACGCAC-3'). The forward primer introduced an Ncol recognition site (underlined) and two neutral changes (bold nucleotides) to enable optimal codon usage during overexpresson in E. coli; the reverse primer introduced a His6-tag coding sequence (underlined) at the $3^{\prime}$ end. After digestion with Ncol, this $1.2 \mathrm{~kb}$ PCR fragment was cloned into pET-33b that had been digested with EcoRI, filled in with Klenow, and then digested with Ncol.

During the course of our investigation, we found a REFSEQ for O. tauri PRORP (XM_003074514; October 16, 2010 NCBI release), which indicated that our initial clone was missing $321 \mathrm{bp}$ at the $5^{\prime}$ end. This $321 \mathrm{bp}$ fragment was then amplified by PCR using genomic DNA and OtNP-N321-F (5'-CCGCTGGACGAAGAAACC-3') and OtNP-N321-R (5'-CCGCTCGTCCACGC-3') and cloned into the previous PET-33b-OtPRORP that had been digested with $\mathrm{Ncol}$ and filled in with Klenow. Sequencing was used to verify the sequence and orientation of this final clone.

For overexpression of O. tauri PRORP, E. coli SHuffle T7 cells (New England Biolabs) were used. In addition to facilitating robust expression of $\mathrm{T7}$ promoter-regulated genes, this strain has been engineered to promote disulfide bond formation in the cytoplasm, an attribute favourable for expression and folding of $O$. tauri PRORP, which contains 15 Cys residues. A single freshly transformed colony was used to inoculate 5 $\mathrm{mL} \mathrm{LB}$ medium containing $35 \mu \mathrm{g} / \mathrm{mL}$ kanamycin and $1 \%(\mathrm{w} / \mathrm{v})$ glucose, and grown overnight at $37^{\circ} \mathrm{C}$ with shaking. This saturated culture was then used to inoculate $500 \mathrm{~mL}$ of $\mathrm{LB}$ medium containing $35 \mu \mathrm{g} / \mathrm{mL}$ kanamycin. The cells were grown at $37^{\circ} \mathrm{C}$ with shaking to Abs600 0.7 and subsequently induced with $1 \mathrm{mM}$ IPTG at $23^{\circ} \mathrm{C}$ for $16 \mathrm{~h}$. The cells were harvested by centrifugation and stored at $-80^{\circ} \mathrm{C}$ until further use.

The above cell pellet was re-suspended in $40 \mathrm{ml}$ of buffer $\mathrm{A}$ [ $20 \mathrm{mM}$ sodium phosphate ( $\mathrm{pH} 7.2$ ), $0.2 \mathrm{mM}$ PMSF] supplemented with $1 \mathrm{mM}$ EDTA and four complete protease inhibitor cocktail tablets (Roche Applied Science). The cell suspension was sonicated and centrifuged $\left(30,000 \mathrm{~g}, 20 \mathrm{~min}, 4^{\circ} \mathrm{C}\right)$ to yield a clarified cell lysate. Five units of DNase I and $10 \mathrm{mM} \mathrm{MgCl} 2$ were added to this lysate and incubated on ice for $30 \mathrm{~min}$. Subsequent to filtration through a $0.45 \mu \mathrm{m}$ filter, this extract was loaded on a pre-equilibrated $1 \mathrm{~mL} \mathrm{Q}$ Sepharose (GE Healthcare) column. An ÄKTA FPLC purifier (GE Healthcare) was used for all subsequent chromatographic procedures. The bound proteins were eluted with a 0.01-1 M NaCl gradient in buffer $A$. O. tauri PRORP-containing fractions ( $\sim 25-600 \mathrm{mM} \mathrm{NaCl}$ ) were identified using SDS-PAGE analysis, pooled and loaded on a pre-equilibrated $1 \mathrm{~mL}$ Chelating HP (GE Healthcare) column that had been charged with NiSO4. The bound proteins were eluted with a 10-150 mM imidazole gradient in buffer A containing $0.5 \mathrm{M}$ $\mathrm{NaCl}$, and highly pure O. tauri PRORP eluted between 100 and $150 \mathrm{mM}$ imidazole. Purified O. tauri PRORP 
was dialyzed into $30 \mathrm{mM}$ HEPES ( $\mathrm{pH} 7.6$ ), $30 \mathrm{mM} \mathrm{KCl}, 6 \mathrm{mM} \mathrm{MgCl}$. The concentration of O. tauri PRORP was calculated using its extinction coefficient and absorbance at $280 \mathrm{~nm}$.

\section{Results}

\section{Bacterial-like RPP in prasinophyte nuclear genomes}

Since a bacterial RPP-like gene has not been reported in Eukarya, we inquired if it could be found in a basal, ancient clade such as Prasinophyceae. There is a hypothetical protein with significant homology to bacterial RPP in the nuclear genomes of $O$. tauri and four other prasinophyte algae: Ostreococcus lucimarinus, Ostreococcus sp. RCC809, Micromonas pusilla, and Micromonas sp. RCC299 (Fig. 1a). Although the bacterial RPP is typically $<150$ aa residues (e.g., E. coli RPP, 119 aa), the prasinophyte homologs are significantly larger (164-393 aa; Fig. 1a) and therefore have sequences/domains in addition to the bacterial RPP-like sequence. These additional domains show no significant similarity to other proteins or among themselves, except for a short homologous segment between M. pusilla and M. sp. RCC299 (Fig. 1a). Further examination of these prasinophyte genes highlights other interesting features. First, in the two Micromonas RPPs, which are encoded by intron-containing sequences, the bacterial RPP-like domain is encoded by a single exon, suggesting exon shuffling as a possible mechanism by which this sequence was acquired. Second, there is an N-terminal appendage of 85 and 77 aa, respectively, to the bacterial RPP-like sequence in $\mathrm{O}$. tauri and Ostreococcus sp. RCC809. Although some algorithms predict these $\mathrm{N}$-terminal extensions to encode an organellar transit peptide, we are hesitant to draw a firm inference in this regard due to the low confidence in accurately predicting algal transit peptides.

\section{Functional validation of the bacterial-like RPP in prasinophytes}

The predicted coding sequence of $\mathrm{O}$. tauri RPP was amplified by PCR and cloned into pET-33b, upstream of a sequence encoding the His6 tag to enable overexpression in E. coli BL21(DE3) cells and subsequent purification by immobilized metal (nickel)-affinity chromatography (IMAC). Three bands were detected in the affinity-purified fraction (Fig. 1b, left; 34, 30 and 24 kDa). Although the expected size for O. tauri RPPHis6 is $27.6 \mathrm{kDa}$, we postulated that it corresponds to the $34 \mathrm{kDa}$ band (the aberrant migration in SDS-PAGE likely due to its high isoelectric point of 10.5). The two smaller proteins might be $\mathrm{N}$-terminally proteolyzed products of $\mathrm{O}$. tauri RPP based on their co-purification with the putative full-length protein on IMAC and the fact that the His6 tag is at the C-terminus. Since the three proteins were readily detectable even in crude extracts of overexpressing cultures (before the start of purification), O. tauri RPP is probably subject to processing in E. coli. When the final purified preparation containing all three proteins was subjected to MALDI-TOF mass spectrometry, we determined that the longest protein (top band, $T$ ) has a size expected for the full-length protein lacking the first methionine, and the shorter proteins correspond to $\mathrm{N}$-terminal deletions of 14 aa (middle band, M) or 66 aa (bottom band, B). Although the preparation with all three polypeptides could reconstitute with bacterial RPRs (see below), we gel-purified the three proteins individually (Fig. 1b, right) to ascertain if all three were functional.

We assayed each of these three recombinant O. tauri RPPs for their ability to reconstitute with the E. coli RPR to form a functional heterologous holoenzyme. Because O. tauri RPP appears to have an organellar transit peptide and might support a mitochondrial function, we cloned the mitochondrial pretRNALeu(GAG) from $\mathrm{O}$. tauri and employed it as a substrate. Indeed, all three proteins could enhance cleavage of pre-tRNALeu by E. coli RPR; a tobacco chloroplast pre-tRNAGly (GCC) was also efficiently cleaved (data not shown). Under conditions optimal for E. coli RNase P activity, the holoenzyme assembled from $\mathrm{O}$. 
tauri RPP-T and E. coli RPR displayed a turnover number one-fifth of that observed with E. coli RNase P using pre-tRNALeu as the substrate ( $\sim 12$ vs. 56 min-1; Fig. 2). Since the deletion derivatives of $O$. tauri RPP lacking the N-terminal 14 or 66 aa are $70 \%$ as active as the full length (Fig. 2), the N-terminal 66 aa residues appear dispensable for pre-tRNA cleavage in vitro. These findings are not unexpected since a sequence alignment (Fig. 1a) reveals that the region of homology between $\mathrm{O}$. tauri and E. coli RPP starts only at around residue 88 in the former.

We also performed reconstitution assays with the mixture of the three affinity-purified O. tauri RPPs and RPRs from two cyanobacteria, Synechocystis sp. PCC6803 and Anabaena sp. PCC7120 (Vioque 1992; Pascual and Vioque 1996). These heterologous reconstitutions are as active as the corresponding homologous reconstitutions under single-turnover conditions with an E. coli pre-tRNATyr as substrate (Fig. 3).

Finally, we assessed if O. tauri RPP is functional in E. coli. For this purpose, we employed E. coli BL21(DE3)A49, a strain in which the R46H mutation in the RPP confers thermosensitivity (ts). Since growth is abolished at $43^{\circ} \mathrm{C}$ due to the inability of the RPP R46H mutant to support RNase P holoenzyme assembly, a plasmid that overexpresses a functional RPP can rescue this strain's ts phenotype (Jovanovic et al. 2002). We exploited this genetic complementation assay to investigate if the O. tauri RPP can functionally replace its $\mathrm{E}$. coli counterpart. Indeed, this is the case as attested by the robust growth at $43^{\circ} \mathrm{C}$ of $\mathrm{E}$. coli BL21(DE3)A49 transformed with pET-33b-OtRPP but not with the empty vector pET-33b (Fig. 4).

\section{O. tauri RPP is expressed in vivo}

While the heterologous reconstitution and in vivo complementation revealed the potential of O. tauri RPP to support bacterial RNase $\mathrm{P}$ catalysis, we sought to gain evidence for its expression in $\mathrm{O}$. tauri. We isolated total RNA from 0 . tauri cells and amplified by RT-PCR the O. tauri RPP cDNA using gene-specific primers. An amplified product of the expected size was observed (Fig. 5a; 722 bp), whose identity was unambiguously established by DNA sequencing (data not shown). To confirm that $\mathrm{O}$. tauri RPP is indeed synthesized in vivo, we first prepared antibodies against the purified O. tauri RPP (mixture of the three proteins; Fig. 1b) and performed western analysis of $O$. tauri cell extracts. We detected a protein of $\sim 34 \mathrm{kDa}$ (Fig. 5b), similar to the size expected for the full-length 0 . tauri RPP (compare Fig. $4 \mathrm{~b}$ with $1 \mathrm{~b}$ ), an assertion further validated by western analysis of the recombinant versions (not shown).

\section{Which RNA catalyst is aided by 0 . tauri bacterial-like RPP?}

Our next objective was to investigate the possible RPRs whose function might either depend on or be aided by O. tauri RPP. Given the bacterial origins of organelles and the similarity of $\mathrm{O}$. tauri RPP to bacterial RPP, we investigated whether $O$. tauri RPP could be a subunit of organellar RNase P.

While an RPR gene has already been annotated in the sequenced O. tauri mitochondrial genome (Fig. 6), we successfully identified a bacterial RPR-like gene in the chloroplast genome (Fig. 6; accession number CR954199, complementary strand positions 4,980 to 5,307). These findings are not surprising since genes coding for bacterial-like RPRs have been previously identified in the organellar genomes of Nephroselmis olivacea, another prasinophyte alga (Turmel et al. 1999a, b). Moreover, the organellar genomes in O. tauri and N. olivacea encode a near-complete suite of tRNAs, thus accounting for the need for RNase P activity in these organelles.

The O. tauri mitochondrial RPR is $269 \mathrm{nts}$ long and has a $37 \%$ GC content, while the plastid RPR is 327 nts long with $29 \%$ GC content (Fig. 6a). The predicted secondary structures of these O. tauri RPRs (Fig. 6a) 
agree with the bacterial consensus and contain all the universally conserved nucleotides (Chen and Pace 1997; Brown 1999; Marquez et al. 2005; Gopalan 2007). However, the secondary structure of these AU-rich O. tauri organellar RPRs, when compared to bacterial prototypes, show notable differences that likely account for the absence of crucial tertiary interactions essential for realizing pre-tRNA cleavage activity in vitro (McClain et al. 2010; Reiter et al. 2010).

The bacterial RPR, which is catalytically active in vitro, generates an active conformation through several GNRA tetraloop:helix docking tertiary contacts (L9:P1, L14:P8, L18:P8; L and P refer to loops and paired regions, respectively). In addition, pseudoknots (e.g., P6) aid the overall fold while other regions (e.g., L15) engage in sequence-specific substrate recognition (Reiter et al. 2010). Most of these attributes are absent in the O. tauri organellar RPRs. The O. tauri mitochondrial RPR is missing the P16/P17 helices and therefore also the pseudoknot generated by helix P6; it also lacks the P12 and P13 helices. Moreover, L9, typically a conserved, helix-stabilizing GNRA tetraloop in bacterial RPRs, is replaced with an AAGA tetraloop. The O. tauri plastid RPR lacks the P15 helix present in bacterial counterparts. In addition, L9 and L14 consist of UUG and ACCC in lieu of the typically conserved GNRA tetraloops at both locations that are involved in functionally important tertiary interactions (Pomeranz Krummel and Altman 1999). The GGU sequence in L15 of the bacterial RPR, which pairs with the 3'-terminal D73C74C75A76 motif in the pre-tRNA substrate (Kirsebom and Svard 1994; Kirsebom 2007), is also absent in both O. tauri organellar RPRs. Overall, while we appreciated that these structural differences in O. tauri organellar RPRs might undermine their ability to generate a native fold required for robust catalytic activity (in the absence of cognate protein factors), we did pursue pre-tRNA cleavage assays in vitro (see below).

Prior to embarking on biochemical studies, we inquired if the putative $\mathrm{O}$. tauri organellar RPRs are expressed in vivo. RT-PCR using gene-specific oligonucleotides and total RNA as the template revealed that these two non-coding RNAs are indeed expressed in O. tauri (Fig. 6b). DNA sequencing of these RT-PCR products, which encompass most of the predicted RPR sequences, confirmed their identity. We assayed these $\mathrm{O}$. tauri organellar RPRs under a number of different conditions (including different pre-tRNA substrates, temperature, $\mathrm{pH}$, and range of divalent/monovalent ion concentrations) but have been unable to detect any pre-tRNA cleavage activity (data not shown). These RPRs also failed to form any functional holoenzymes with either O. tauri or bacterial RPPs (Fig. 3; data not shown). These findings parallel previous futile attempts with several organellar RPRs (Pascual and Vioque 1999a; De la Cruz and Vioque 2003) -the sole exception has been the weak enzymatic activity detected in the case of the plastid RPR from Cyanophora paradoxa (Li et al. 2007).

We can speculate on some reasons for the lack of activity of $\mathrm{O}$. tauri organellar RPRs without and with $\mathrm{O}$. tauri RPP. First, their low GC content $(<37 \%)$ likely results in mis-folding/instability of in vitro transcribed preparations and therefore, a non-functional structure. Second, despite the resemblance of their secondary structure to other RPRs and the presence of universally conserved nucleotides believed to constitute the active site, these organellar RPRs lack some of the tertiary structure-stabilizing elements present in the bacterial RPR counterparts, which display robust activity. Third, the failure of $\mathrm{O}$. tauri RPP to reconstitute with cognate organellar RPRs might reflect either the need for additional protein cofactors to realize RNase $P$ activity or the possibility that it supports a function unrelated to tRNA maturation. These speculations can be verified only when the native organellar RNase $\mathrm{P}$ is purified and characterized.

\section{PRORP in prasinophytes}


O. tauri and other prasinophyte nuclear genomes encode a $\sim 60 \mathrm{kDa}$ protein homolog of Arabidopsis PRORP-1 (Gobert et al. 2010), which was shown to localize in mitochondria and chloroplasts and to catalyze pre-tRNA 5'-processing in vitro (under single-turnover conditions). The open reading frame (ORF) encoding O. tauri PRORP ( $57 \mathrm{kDa}$ ) was amplified by PCR and cloned into $\mathrm{pET}-33 \mathrm{~b}$ with a sequence encoding the His 6 tag to enable overexpression in E. coli SHuffle T7 cells and purification to near homogeneity using tandem anion exchange chromatography and IMAC (Fig. 7a). This recombinant O. tauri PRORP promotes accurate in vitro 5'-processing of pre-tRNALeu (data not shown) and pre-tRNAGly (Fig. 7b). Although the activity we observed were in assays performed under single-turnover conditions (akin to the previous study on Arabidopsis PRORP-1), our result corroborates the finding of a single polypeptide capable of tRNA 5'maturation and sets the stage for detailed kinetic studies to compare the catalytic efficiency of different PRORP- and RNP-based RNase P variants.

\section{Discussion}

An inventory of the RNase P variants in O. tauri (Fig. 8) highlights the striking diversity in this smallest freeliving eukaryote. First, a bacterial RPP-like protein is encoded by the $\mathrm{O}$. tauri nuclear genome. Although this protein is synthesized inside the cell and a recombinant version is functional with bacterial RPRs as assessed by in vitro reconstitution assays (Figs. 2, 3), further studies are needed to investigate if this protein in O. tauri is imported into mitochondria/plastid for subsequent assembly with the organellar RPRs (either alone or with additional protein cofactors). However, the size of the protein expressed in vivo is that expected for the full-length protein (Fig. 5), arguing against the presence of a cleavable transit peptide for import into organelles. It is not possible, however, to rule out aberrant migration arising from posttranslational modifications of a shorter version. Second, the $\mathrm{O}$. tauri mitochondrial and chloroplast genomes each encode a bacterial RPR-like RNA, which is expressed in vivo (Fig. 6). However, the exact functions of these RPRs remain to be determined. Third, we have now demonstrated that a recombinant version of $\mathrm{O}$. tauri PRORP supports pre-tRNA 5'-processing in vitro (Fig. 7), although the subcellular locale of this protein in O. tauri has not been determined. Lastly, the full set of eukaryal (nuclear) RPPs was not found in any of the five prasinophyte algal genomes. Only POP5 and RPP30 could be identified with confidence in all five strains. In addition, there is no report of a putative O. tauri nuclear RPR (at least one resembling those found in eukaryotes ranging from yeast to human). In fact, the identity of plant/algal nuclear RPR remains unknown (Rosenblad et al. 2006).

Several interesting attributes and questions emerge from this growing appreciation of the variability of RNase $\mathrm{P}$ in $\mathrm{O}$. tauri and, more broadly, in all domains of life. First, the discovery of a bacterial-like RPP in prasinophyte algae was unanticipated; a comprehensive phylogenetic study with additional taxa is required to investigate if this represents an instance of horizontal gene transfer from bacteria that co-habitat with 0 . tauri. In these prasinophyte proteins, the bacterial RPP-like domain is more similar to each other than to any bacterial RPP, suggesting that the acquisition of this domain happened once in a common prasinophyte ancestor. Our findings echo the recurring theme in recent studies on the surprising mixed ancestry of genes in some eukaryotes, especially phytoplankton. For instance, nitrogen transporters and related assimilation genes in Micromonas unexpectedly revealed that these genes share plant, algal or bacterial cousins (McDonald et al. 2010). It was postulated that the wide-ranging origins of certain genes might contribute to the fitness landscape of phytoplankton such as Micromonas and Ostreococcus, especially their ability to utilize energy sources that show seasonal variations in the oceanic habitat (McDonald et al. 2010). In a related vein, it is possible that the presence of multiple forms of RNase $P$ (either RNP- or protein-based) 
with distinct RNA processing traits affords a selective advantage in the specific ecological niche of these organisms.

Second, the diverse subunit make-up of RNase $P$ in nature suggests multiple routes for generating its active site. What evolutionary forces and payoffs might underlie this pliability to employ a structurally diverse ensemble? For example, is it the high evolutionary rate of organelles, the plasticity of their genomes, and/or altered substrate specificity that has molded the extant organellar RNase $P$ make-up? In this respect, it should be noted that several tRNA genes in Ostreococcus and Micromonas are permuted (Maruyama et al. 2010), and their processing by RNase $P$ might require interactions of the enzyme with unusual structures in the permuted pre-tRNAs. The presence of diverse RNase $P$ enzymes might afford a "divide and conquer" approach to deal with biogenesis/maturation of unusual pre-tRNA and non-coding RNA substrates.

Lastly, since the single plant organellar RNase P protein (PRORP, 50 to $60 \mathrm{kDa}$ ) has homologs in evolutionarily distant eukaryotic lineages and can functionally substitute for the $135 \mathrm{kDa}$ RNP complex in bacteria (Gobert et al. 2010), it is perplexing why cells, which now rely almost exclusively on proteins for catalytic and structural roles, have retained RNA-mediated catalysis at all in RNase P. Did retention of an RNA then confer advantages such as optimal recognition of RNA substrates through base pairing? Or is the RNP form better suited for enmeshing in a regulated network of macromolecular machineries mediating different aspects of gene expression (Reiner et al. 2006, 2008)? While the use of proteins and RNPs to perform the same biological task in different settings attests to nature's versatility in designing catalysts, the daunting challenge is to understand the basis for these choices.

\section{Acknowledgments}

We thank Dr. M. L. S. Raj for cloning the tobacco chloroplast pre-tRNAGly(GCC) in pUC19. This work was supported by Ministerio de Ciencia e Innovación, Spain, and European Regional Fund [BFU2007-60651 (to A.V.)], Junta de Andalucía, Spain [P06-CVI-01692 (to A.V.)], European Union [ASSEMBLE grant agreement no. 227799 (to A.V.)], and the National Science Foundation [MCB-0238233 and MCB-0843543 (to V.G.)]. Pilar Bernal-Bayard was supported by a fellowship from Junta de Andalucía, Spain. 


\section{References}

Altschul SF, Gish W, Miller W, Myers EW, Lipman DJ (1990) Basic local alignment search tool. J Mol Biol 215:403-410

Brown JW (1999) The ribonuclease P database. Nucleic Acids Res 27:314

Chen JL, Pace NR (1997) Identification of the universally conserved core of ribonuclease P RNA. RNA 3:557560

Chenna R, Sugawara H, Koike T, Lopez R, Gibson TJ, Higgins DG, Thompson JD (2003) Multiple sequence alignment with the Clustal series of programs. Nucleic Acids Res 31:3497-3500

De la Cruz J, Vioque A (2003) A structural and functional study of plastid RNAs homologous to catalytic bacterial RNase P RNA. Gene 321:47-56

Derelle E, Ferraz C, Rombauts S, Rouze P, Worden AZ, Robbens S, Partensky F, Degroeve S, Echeynie S, Cooke R, Saeys Y, Wuyts J, Jabbari K, Bowler C, Panaud O, Piegu B, Ball SG, Ral JP, Bouget FY, Piganeau G, De Baets B, Picard A, Delseny M, Demaille J, Van de Peer Y, Moreau H (2006) Genome analysis of the smallest free-living eukaryote Ostreococcus tauri unveils many unique features. Proc Natl Acad Sci USA 103:1164711652

Esakova O, Krasilnikov AS (2010) Of proteins and RNA: the RNase P/MRP family. RNA 16:1725-1747

Evans D, Marquez SM, Pace NR (2006) RNase P: interface of the RNA and protein worlds. Trends Biochem Sci 31:333-341

Gobert A, Gutmann B, Taschner A, Gossringer M, Holzmann J, Hartmann RK, Rossmanith W, Giege P (2010) A single Arabidopsis organellar protein has RNase P activity. Nat Struct Mol Biol 17:740-744

Gopalan V (2007) Uniformity amid diversity in RNase P. Proc Natl Acad Sci USA 104:2031-2032

Guerrier-Takada C, Li Y, Altman S (1995) Artificial regulation of gene expression in Escherichia coli by RNase P. Proc Nat Acad Sci USA 92:11115-11119

Hardy E, Castellanos-Serra LR (2004) "Reverse-staining" of biomolecules in electrophoresis gels: analytical and micropreparative applications. Anal Biochem 328:1-13

Harlow E, Lane D (1988) Antibodies: a laboratory manual. Cold Spring Harbor Laboratory Press, Cold Spring Harbor

Holzmann J, Frank P, Loffler E, Bennett KL, Gerner C, Rossmanith W (2008) RNase P without RNA: identification and functional reconstitution of the human mitochondrial tRNA processing enzyme. Cell 135:462-474

Jarrous N, Gopalan V (2010) Archaeal/eukaryal RNase P: subunits, functions and RNA diversification. Nucleic Acids Res 38:7885-7894

Jovanovic M, Sanchez R, Altman S, Gopalan V (2002) Elucidation of structure-function relationships in the protein subunit of bacterial RNase $\mathrm{P}$ using a genetic complementation approach. Nucleic Acids Res 23:5065-5073 
Keller MD, Selvin RC, Claus W, Guillard RRL (1987) Media for the culture of oceanic ultraphytoplankton. J Phycol 23:633-638

Kirsebom LA (2007) RNase P RNA mediated cleavage: substrate recognition and catalysis. Biochimie 89:1183-1194

Kirsebom LA, Svard SG (1994) Base pairing between Escherichia coli RNase P RNA and its substrate. EMBO J 13:4870-4876

Lai LB, Vioque A, Kirsebom LA, Gopalan V (2010) Unexpected diversity of RNase P, an ancient tRNA processing enzyme: challenges and prospects. FEBS Lett 584:287-296

Li D, Willkomm DK, Schön A, Hartmann RK (2007) RNase P of the Cyanophora paradoxa cyanelle: a plastid ribozyme. Biochimie 89:1528-1538

Liu F, Altman S (2010) Ribonuclease P. Springer-Verlag, New York

Marquez SM, Harris JK, Kelley ST, Brown JW, Dawson SC, Roberts EC, Pace NR (2005) Structural implications of novel diversity in eucaryal RNase P RNA. RNA 11:739-751

Maruyama S, Sugahara J, Kanai A, Nozaki H (2010) Permuted tRNA genes in the nuclear and nucleomorph genomes of photosynthetic eukaryotes. Mol Biol Evol 27:1070-1076

McClain WH, Lai LB, Gopalan V (2010) Trials, travails and triumphs: an account of RNA catalysis in RNase P. J Mol Biol 397:627-646

McDonald SM, Plant JN, Worden AZ (2010) The mixed lineage nature of nitrogen transport and assimilation in marine eukaryotic phytoplankton: a case study of Micromonas. Mol Biol Evol 27:2268-2283

Morales MJ, Dang YL, Lou YC, Sulo P, Martin NC (1992) A $105 \mathrm{kDa}$ protein is required for yeast mitochondrial RNase P activity. Proc Natl Acad Sci USA 89:9875-9879

Palenik B, Grimwood J, Aerts A, Rouze P, Salamov A, Putnam N, Dupont C, Jorgensen R, Derelle E, Rombauts S, Zhou K, Otillar R, Merchant SS, Podell S, Gaasterland T, Napoli C, Gendler K, Manuell A, Tai V, Vallon O, Piganeau G, Jancek S, Heijde M, Jabbari K, Bowler C, Lohr M, Robbens S, Werner G, Dubchak I, Pazour GJ, Ren Q, Paulsen I, Delwiche C, Schmutz J, Rokhsar D, Van de Peer Y, Moreau H, Grigoriev IV (2007) The tiny eukaryote Ostreococcus provides genomic insights into the paradox of plankton speciation. Proc Natl Acad Sci USA 104:7705-7710

Pascual A, Vioque A (1996) Cloning, purification and characterization of the protein subunit of ribonuclease P from the cyanobacterium Synechocystis sp. PCC 6803. Eur J Biochem 241:17-24

Pascual A, Vioque A (1999a) Functional reconstitution of RNase P activity from a plastid RNA subunit and a cyanobacterial protein subunit. FEBS Lett 442:7-10

Pascual A, Vioque A (1999b) Substrate binding and catalysis by ribonuclease $P$ from cyanobacteria and Escherichia coli are affected differently by the $3^{\prime}$ terminal CCA in tRNA precursors. Proc Natl Acad Sci USA 96:6672-6677 
Pomeranz Krummel DA, Altman S (1999) Verification of phylogenetic predictions in vivo and the importance of the tetraloop motif in a catalytic RNA. Proc Natl Acad Sci USA 96:11200-11205

Reiner R, Ben-Asouli Y, Krilovetzky I, Jarrous N (2006) A role for the catalytic ribonucleoprotein RNase P in RNA polymerase III transcription. Genes Dev 20:1621-1635

Reiner R, Krasnov-Yoeli N, Dehtiar Y, Jarrous N (2008) Function and assembly of a chromatin-associated RNase $P$ that is required for efficient transcription by RNA polymerase I. PLoS One 3:e4072

Reiter NJ, Osterman A, Torres-Larios A, Swinger KK, Pan T, Mondragon A (2010) Structure of a bacterial ribonuclease $\mathrm{P}$ holoenzyme in complex with tRNA. Nature 468:784-789

Rosenblad MA, Lopez MD, Piccinelli P, Samuelsson T (2006) Inventory and analysis of the protein subunits of the ribonucleases $\mathrm{P}$ and MRP provides further evidence of homology between the yeast and human enzymes. Nucleic Acids Res 34:5145-5156

Schedl P, Primakoff P (1973) Mutants of Escherichia coli thermosensitive for the synthesis of transfer RNA. Proc Natl Acad Sci USA 70:2091-2095

Tsai HY, Lai LB, Gopalan V (2002) A modified pBluescript-based vector for facile cloning and transcription of RNAs. Anal Biochem 303:214-217

Turmel M, Lemieux C, Burger G, Lang BF, Otis C, Plante I, Gray MW (1999a) The complete mitochondrial DNA sequences of Nephroselmis olivacea and Pedinomonas minor. Two radically different evolutionary patterns within green algae. Plant Cell 11:1717-1730

Turmel M, Otis C, Lemieux C (1999b) The complete chloroplast DNA sequence of the green alga Nephroselmis olivacea: insights into the architecture of ancestral chloroplast genomes. Proc Natl Acad Sci USA 96:10248-10253

Vioque A (1992) Analysis of the gene encoding the RNA subunit of ribonuclease P from cyanobacteria. Nucleic Acids Res 20:6331-6337

Vioque A, Arnez J, Altman S (1988) Protein-RNA interactions in the RNase P holoenzyme from Escherichia coli. J Mol Biol 202:835-848

Walker SC, Engelke DR (2006) Ribonuclease P: the evolution of an ancient RNA enzyme. Crit Rev Biochem Mol Biol 41:77-102

Wang G, Chen HW, Oktay Y, Zhang J, Allen EL, Smith GM, Fan KC, Hong JS, French SW, McCaffery JM, Lightowlers RN, Morse HC 3rd, Koehler CM, Teitell MA (2010) PNPASE regulates RNA import into mitochondria. Cell 142:456-467

Worden AZ, Lee JH, Mock T, Rouze P, Simmons MP, Aerts AL, Allen AE, Cuvelier ML, Derelle E, Everett MV, Foulon E, Grimwood J, Gundlach H, Henrissat B, Napoli C, McDonald SM, Parker MS, Rombauts S, Salamov A, Von Dassow P, Badger JH, Coutinho PM, Demir E, Dubchak I, Gentemann C, Eikrem W, Gready JE, John U, Lanier W, Lindquist EA, Lucas S, Mayer KF, Moreau H, Not F, Otillar R, Panaud O, Pangilinan J, Paulsen I, Piegu B, Poliakov A, Robbens S, Schmutz J, Toulza E, Wyss T, Zelensky A, Zhou K, Armbrust EV, Bhattacharya D, Goodenough UW, Van de Peer Y, Grigoriev IV (2009) Green evolution and dynamic adaptations revealed by genomes of the marine picoeukaryotes Micromonas. Science 324:268-272 


\section{Figure captions}

Figure 1. Bacterial-like RPP in Prasinophyceae. a Alignment of the E. coli RPP sequence with homologs from several prasinophyte genomes. Homologous proteins were identified in the nuclear genome sequence of Micromonas pusilla CCMP1545 (M. pusilla, XM_003057480), Micromonas sp. RCC299 (M. RCC299, XM_002501961), Ostreococcus lucimarinus (O. lucimarinus, XM_001421023), Ostreococcus tauri (O. tauri, XM_003082501), and Ostreococcus sp. RCC809 (O. RCC809, the Joint Genome Institute Database, http://genome.jgi-psf.org/). The alignment was generated with Clustal W (Chenna et al. 2003) and manually refined. The regions that share high similarity with E. coli RPP are boxed. While positions identical in all five prasinophyte proteins are indicated with asterisks above the alignment, those shared with E. coli RPP are indicated with asterisks below the alignment. The black triangles show the position of predicted introns (according to the JGI annotation) in the two Micromonas strains. Underlined is a CCHC zinc-finger motif in M. pusilla RPP; the dotted-line box highlights a segment of similarity between M. pusilla and M. RCC299 RPPs outside the E. coli RPP-like region. b Purification of recombinant O. tauri RPP (OtRPP). Coomassie blue-stained polyacrylamide gels illustrate purity of the OtRPP-containing peak fraction from nickel affinity chromatography (left) and of the individual isolated polypeptides (right). The predicted Nterminus of each polypeptide ( $T$ top, $M$ middle, B bottom), as determined by MALDI-TOF mass spectrometry, is indicated in (a)

Figure 2. Heterologous reconstitution of RNase $P$ activity with $O$. tauri RPP and E. coli RPR. RNase $P$ holoenzymes were assembled using E. coli RPR (EcRPR) and either purified E. coli RPP (EcRPP) or each gelpurified polypeptide of $O$. tauri RPP (OtRPP-T, $-M$, or $-B$ ). The first lane is a negative control with EcRPR in the absence of any protein cofactor, and the "- EcRPR" lanes are controls performed with only the indicated proteins but no RPR. The multiple-turnover reaction rate for each of the four reconstituted holoenzymes is indicated at the bottom of the respective time courses

Figure 3. Heterologous reconstitution of RNase $P$ activity with $O$. tauri RPP and cyanobacterial RPR. Reconstitution of RNase $\mathrm{P}$ activity with purified recombinant RPP and in vitro transcribed RPR from Synechocystis PCC6803 (Sy), Anabaena PCC7120 (An), and O. tauri mitochondria (Ot). Assays were performed under single-turnover conditions (see "Materials and methods" for details). The first lane is a negative control without RPR or RPP, and the "- RPR" lanes are controls performed with only the indicated RPP but no RPR

Figure 4. O. tauri RPP functionally substitutes for a bacterial RPP in vivo. Tenfold serial dilutions of the temperature-sensitive E. coli BL21(DE3)A49 strain harboring pARE7 (expressing E. coli RPP), the empty vector $\mathrm{pET}-33 \mathrm{~b}$, or $\mathrm{pET}-33 \mathrm{~b}-\mathrm{OtRPP}$ (expressing $\mathrm{O}$. tauri RPP) were assessed for growth on LB agar plates at $30^{\circ} \mathrm{C}$ (permissive) or $43^{\circ} \mathrm{C}$ (non-permissive) for $16 \mathrm{~h}$

Figure 5. Expression of the bacterial-like RPP in O. tauri. a Detection of the 722 bp cDNA encoding the 0. tauri RPP by RT-PCR $(+)$, but not by PCR alone $(-)$, in total RNA isolated from 0 . tauri cells. $b$ Western analysis of $\mathrm{O}$. tauri $(\mathrm{Ot})$ total protein extract with polyclonal antibodies raised against $\mathrm{O}$. tauri RPP

Figure 6. RPRs from $\mathrm{O}$. tauri mitochondria and chloroplasts. a Secondary structure models of RPRs from $\mathrm{O}$. tauri mitochondria ( $\mathrm{mt}$; left) and chloroplast (cp; right). Paired regions (helices) are labeled as P1, P2, etc., consecutively from $5^{\prime}$ to $3^{\prime}$ following the nomenclature used for bacterial RPRs. The prefix $L$ refers to loops 
capping paired regions. Universally conserved nucleotides (Chen and Pace 1997; Brown 1999; Marquez et al. 2005; Gopalan 2007) are highlighted with a black circle. Solid lines show long-distance interactions that generate pseudoknots P4 and P6, as well as other tertiary interactions. b Expression of organellar RPRs in O. tauri. Detection of the cDNAs corresponding to the RPR from O. tauri mitochondria (left; $255 \mathrm{bp}$ ) and chloroplast (right; 304 bp) by RT-PCR (+) but not by PCR alone (-) in total RNA isolated from O. tauri cells

Figure 7. Purification and activity of recombinant O. tauri PRORP. a Coomassie blue-stained polyacrylamide gel illustrates purity of the PRORP-containing peak fraction from nickel-affinity chromatography. $b$ PretRNA $5^{\prime}$-processing activity of recombinant $\mathrm{O}$. tauri PRORP. The first lane (-) is a negative control without any enzyme, the second lane $(+)$ is a positive control with $E$. coli RNase $P$, and the last lane (PRORP) is a reaction with $\mathrm{O}$. tauri PRORP

Figure 8. The potential complexity and diversity of RNase $P$ in $O$. tauri. Schematic summarizing the RNase $P$ components encoded by each of the three 0 . tauri genomes. They were identified based on sequence homology 


\section{Figure 1}

\section{a}

M. pusilla

M. RCC299

O. lucimarinus

o. RCC 809

O. tauri

E. coll

E. coli AAFNPATCLHRSRAFAHAPVHPTSAAVPAHRRARVVAWTTSWRARNLTATRAVAEPRGSSANKEDDWDEDEDEVEDDEGFDDDHDGPALGGDKFVKMTHT

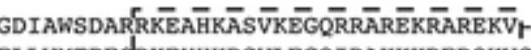
B1 ---1-MASGGWAFGGTRRRARGFGGFGGFGRSLGARASNGDDGVDAALTTVRDDDGASPRDAAMMKEERVGHGGNWGESSGRSGKTPAAFESID 89

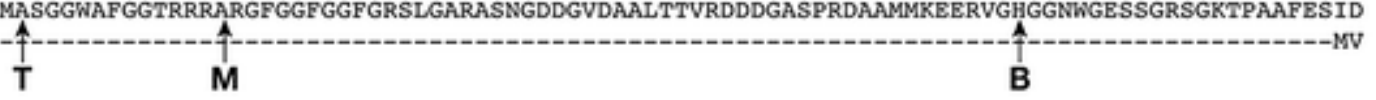

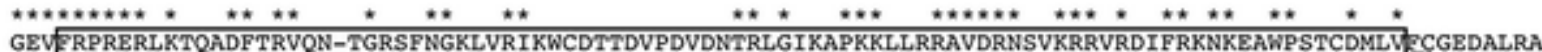

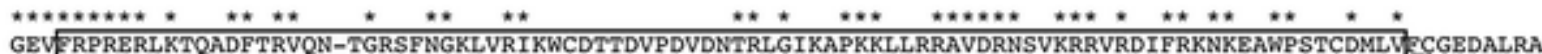
GEWRPRETKSORDFORVMNOCGNFNGKT MRKYCSNEGLXDVDCTRIGIXVPKKFVKRAVDRNLVKRRTREIFRRNKDAMPARTDLTU X GEVFRPRERLKTNADFDRVKR-EGRTYNGAHLRIRAVDNANHEPATCTRIGIVVPKKQVKRAVDRNLIKRRIRHAFRTNKDAWPARVDFIVVNASALEG 115 GEVFRPRERLKTNADFDRVKR-NGRSPNGAHVRIRAVGNEDYEPATCTRVGVVVPKKQLKRAVDRNLVKRRVRHIFRTNKDKWPPRVDPIVFVQKSALEG 180 GEVFRPRERLKTNADFDRVKR-FGRTFNGSHLRIKAVDNASYDAATCTRLGIVVPKKRVRRAVDRNLIKRRIRHVFRTNKDKWPPRVDIIVFAGDTALEG 89 KLAE-PRELRLLTPSQFTFVFQQPQRAGTPQITILGRLNS----LGHPRIGLTVAKKNVRRAHERNRIKRLTRESFRLRQHELPA-MDFVVIV-----KK 91

E. coli

b
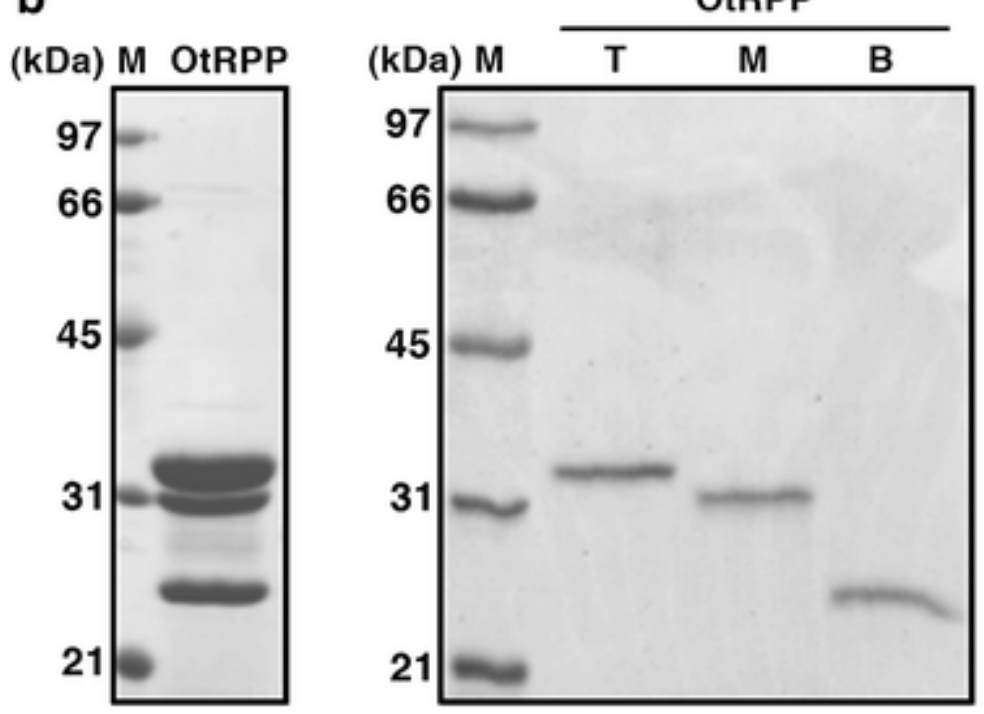


\section{Figure 2}

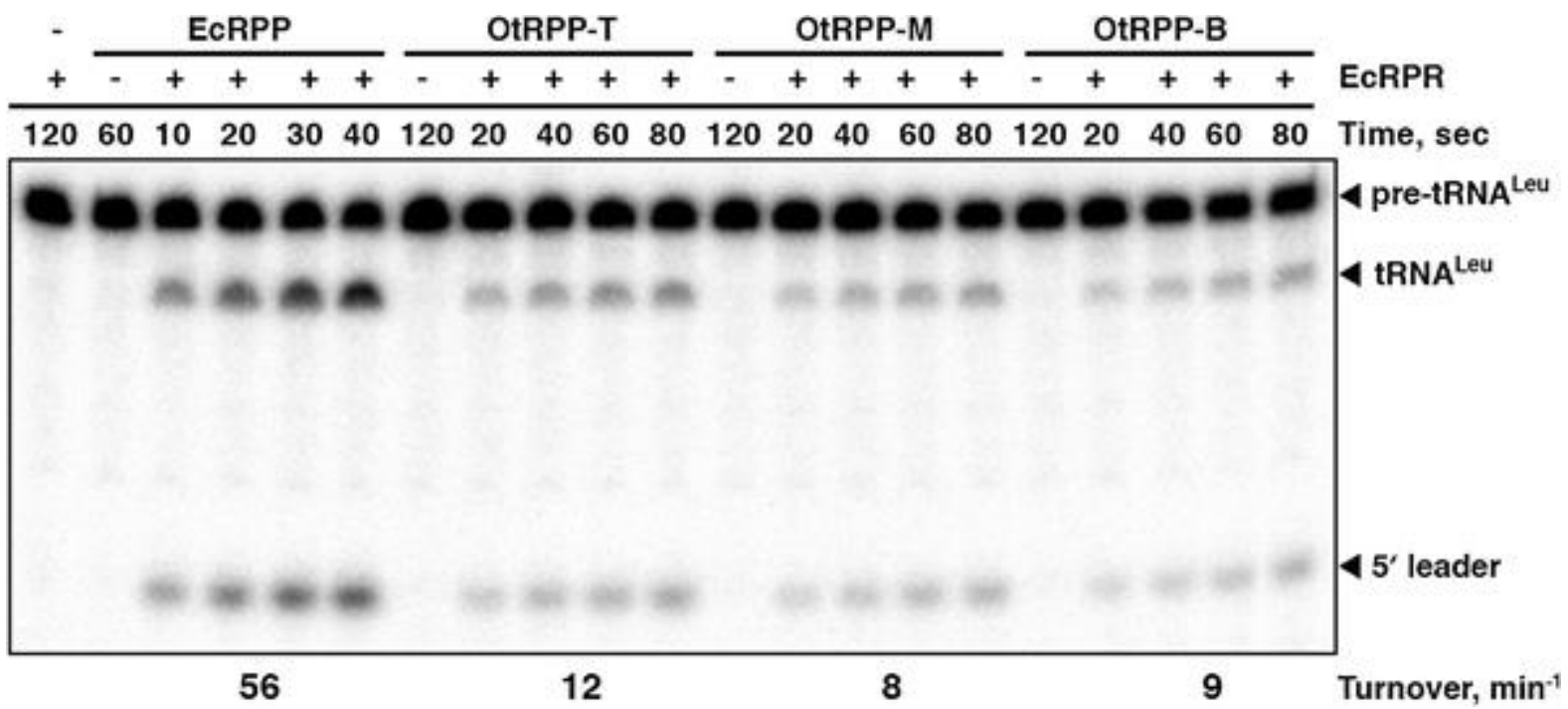


Figure 3

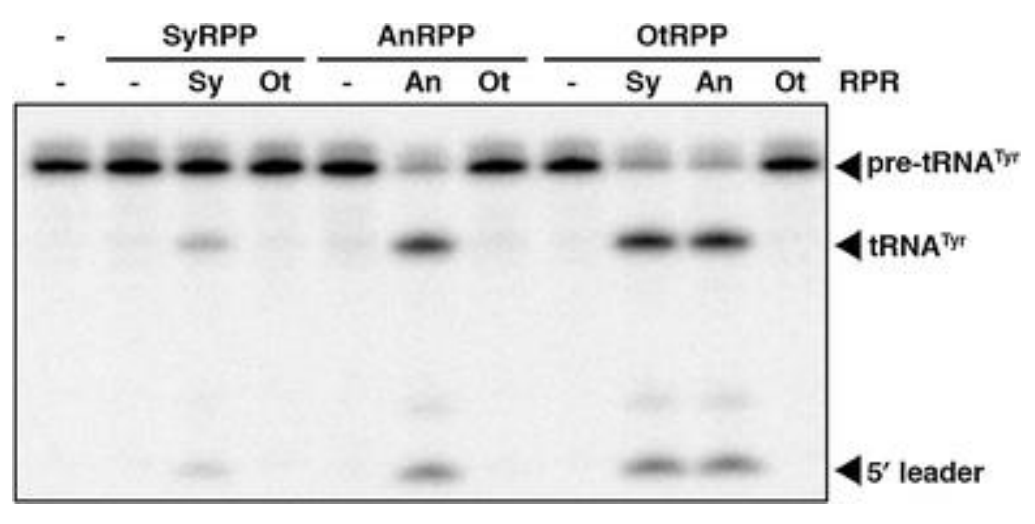


Figure 4

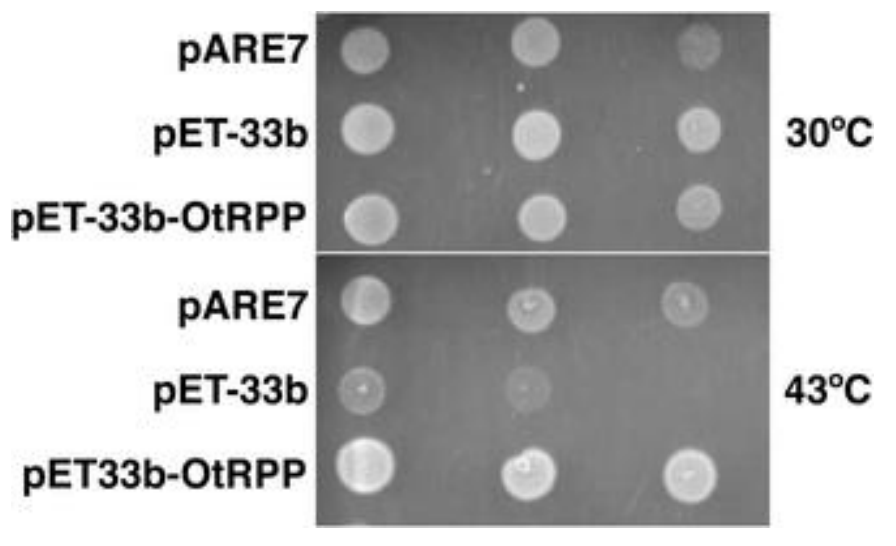


Figure 5
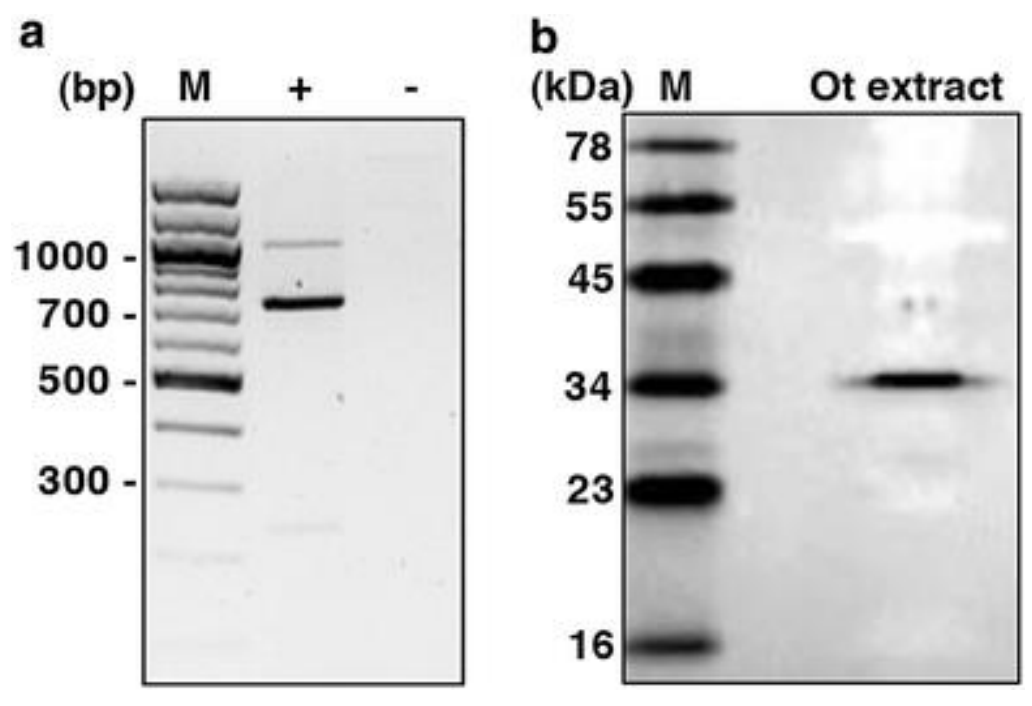
Figure 6

a

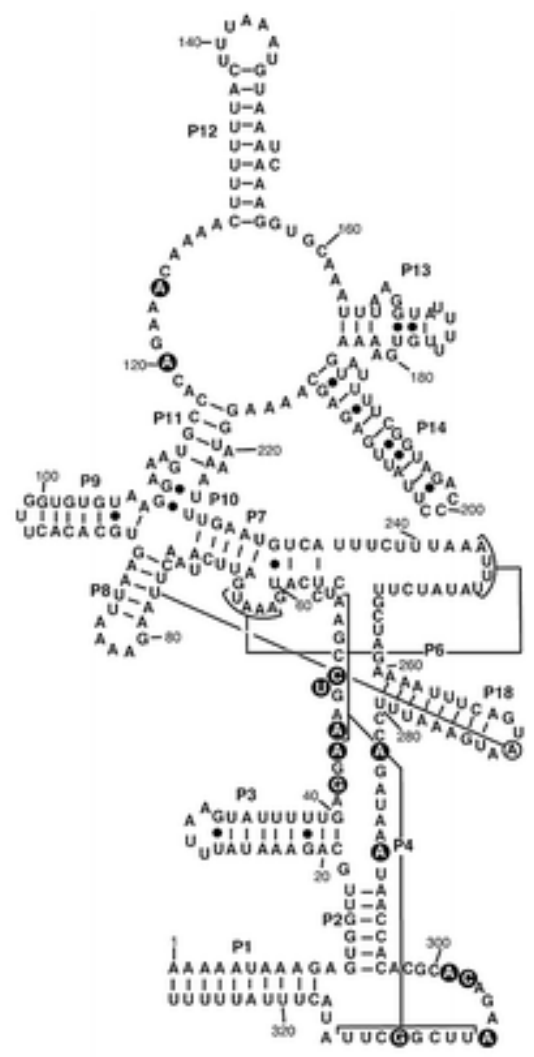

b O. tauri mt RPR

O. tauri cp RPR

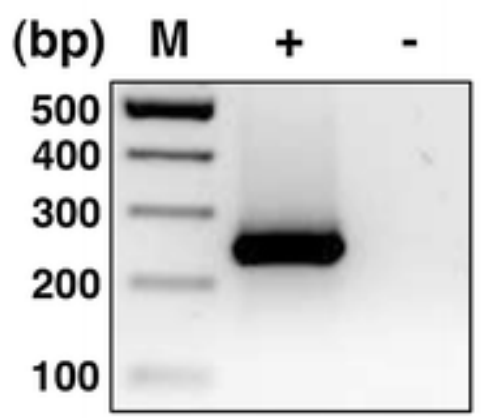

(bp) $\mathrm{M}+$ -

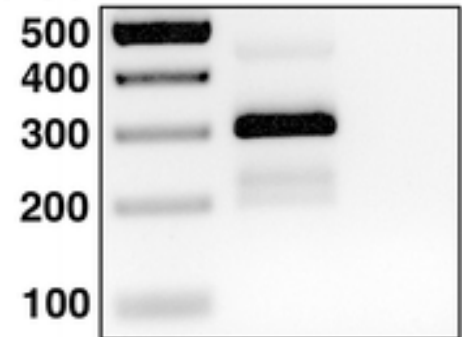




\section{Figure 7}

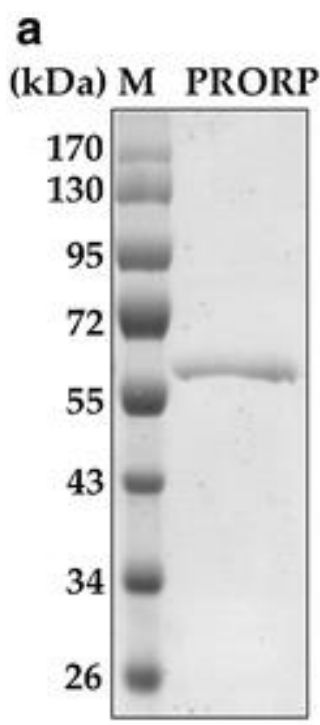

b

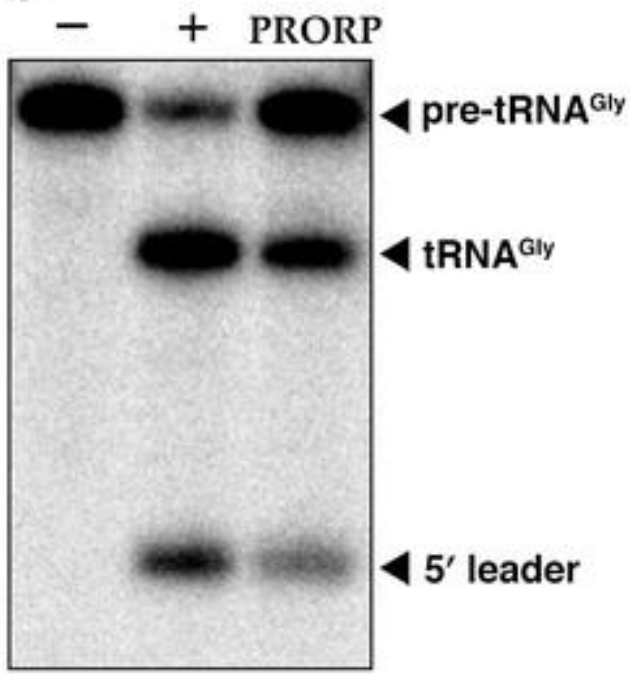


Figure 8

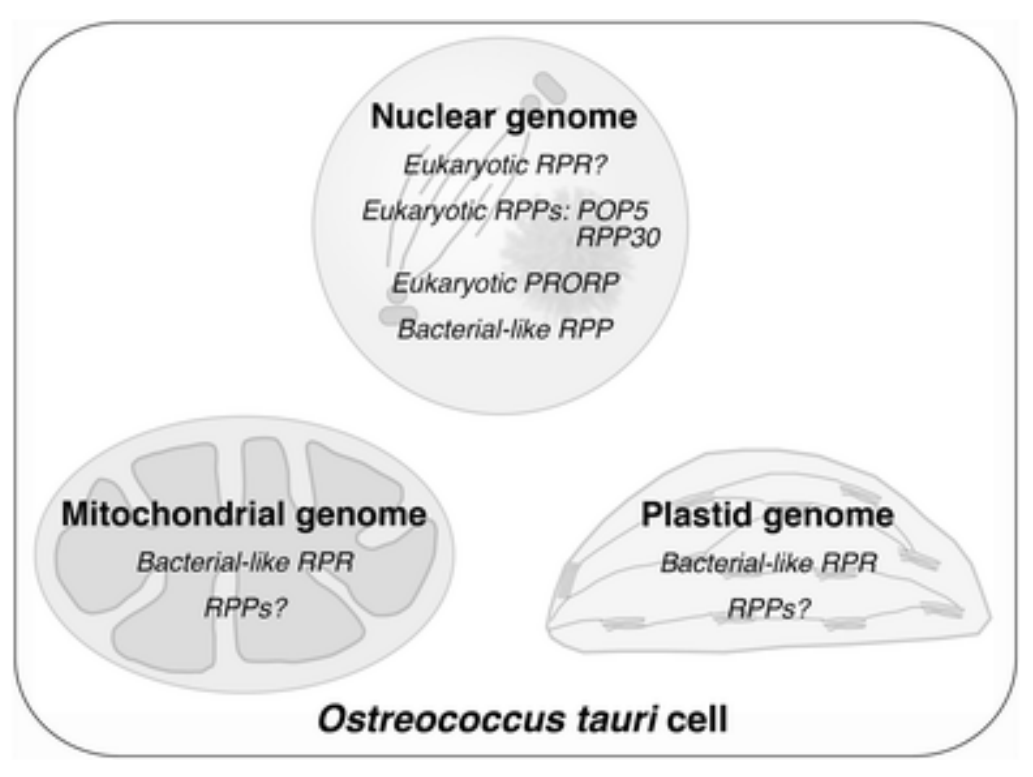

